11. Lugans'ka oblast' u cyfrah. Statystychnyj zbirnyk. Derzhavnyj komitet statystyky Ukrai'ny. Golovne upravlinnja statystyky u Lugans'kij oblasti. Lugans'k 2006-2012 rr.

12. DBN B.2.2-12:2019, Planning and building of territories (Ministry for Communities and Territories Development of Ukraine, Kyiv, 2019)

13.V.M. Sokolenko, O.E. Podljevs'kyj, analiz kolichestvennogo i kachestvennogo sostojanija zelenyh nasazhdenij na territorii zhiloj zastrojki goroda Alchevska Luganskoj oblasti, Zbirnyk naukovyh prac' Donbas'kogo derzhav nogo tehnichnogo universytetu, 1(46), 94-101 (DonSTU, Lysychans'k, 2017)

14. Yu.N. Belokon' Regional'noye planirovaniye - teoriya i praktika. (Logos, Kyiv, 2003)

https://doi.org/10.31713/m1030

\title{
HYPOCHLORITE GOLD LEACHING AN ALTERNATIVE TO CYANIDE TECHNOLOGY
}

Prokopenko V.A.
F.D. Ovcharenko Institute of Biocolloidal Chemistry NAS
of Ukraine, Kyiv, Ukraine; doctor of technical sci., director
Chernenko V.Yu.
National Technical University "Igor Sikorsky Kyiv Polytechnic
Institute", Kyiv, Ukraine; cand. med. sci., professor assistant
of Chemical Technology Faculty
Vorotytsky P.V.
Tsyganovich O.A.
of Ukraine, Kyiv, Ukraine; graduate student
F.D. Ovcharenko Institute of Biocolloidal Chemistry NAS
of Ukraine, Kyiv, Ukraine; PhD, deputy director on scientific work
Volobaiev I.I.
F.D. Ovcharenko Institute of Biocolloidal Chemistry NAS of
Ukraine, Kyiv, Ukraine; PhD, researcher
Abstract
Traditional technologies of gold mining are exhausted due to the depletion of
stocks of conditioned raw materials at functioning gold mining enterprises, in
addition, the preservation or disposal of large-scale waste of these technologies
requires significant financial costs for environmental protection measures.


Recently, the search for alternative methods of gold leaching, which involve the use of non-toxic factors, but which in their physicochemical properties can compete with traditional levels, and especially with cyanides.

The authors of this work investigated the mechanism and kinetics of the process of dissolving metallic gold in chloride-hypochlorite solutions and believe that alkali metal hypochlorites (first of all, sodium hypochlorite $\mathrm{NaOCl}$, which is easily obtained by electrolysis from a solution of food's salt $\mathrm{NaCl}$, or from sea water) are a very promising replacement for cyanide-containing leachates. Two series of experiments were carried out to study sodium hypochlorite as a gold leaching agent using a traditional gold disk and finely dispersed native gold as dissolution objects. Found fundamental differences in methodological techniques when working with a traditional model object and native gold.

The dependences of the dissolution rate on the solution $\mathrm{pH}$, sodium hypochlorite concentration, and temperature are determined. Conditions of the gold surface passivation during its dissolution are discussed. The first-order rate constant of the gold dissolution $k_{i}=0,079-0,4030 h^{-1}$ at temperatures from $277 K$ to $304 K$ and others are calculated. The activation energy from the temperature dependence of the rate constants $(40,3 \mathrm{~kJ} / \mathrm{mol})$ evidences a diffusion-kinetic control of the gold dissolution.

Electron microscopy (using electron probe scanning on an energy dispersive spectrometer) of native gold particles revealed foreign inclusions - adsorbed mineral particles of calcite $\left(\mathrm{CaCO}_{3}\right)$ and, presumably, a surface film consisting of aluminum oxide $\left(\mathrm{Al}_{2} \mathrm{O}_{3}\right)$, which create a significant obstacle to the contact of leaching agents with the surface of the target gold grains.

Quantitative data on the composition of surface adsorption films, formed by model gold electrode dissolution products, are obtained using atomic adsorption spectroscopy.

\section{Introduction}

Cyanidation is still the dominant process for dissolving gold in the mining industry. Despite its high efficiency for gold leaching, it suffers from some major drawbacks including high toxicity and low dissolution rate [1]. The large-scale application of the cyanide solutions poses environmental problems in large areas. Therefore, new alternative solvents for gold are searched for, such as thiourea [2], thiosulfates, polysulfides, halide-derivatives and hypochlorites [1], etc. Leaching of metallic gold is based on a voltage-dependent redox reaction, in which gold acts as an electron donor (anode), and chlorine, which is part of sodium hypochlorite, is an electron acceptor (cathode). The activity of the leaching process depends on many factors, however, the $\mathrm{pH}$ of the medium and the solvent are of fundamental importance, which ensures the proper strength of electrolytes and the electrical conductivity of solutions, as well as allows you to control the direction of the chemical reaction and the yield of final products [3]. A thorough study of the mechanism and kinetics 
of the process of interaction of the surface of metallic gold with sodium hypochlorite $\mathrm{NaOCl}$ solutions at different $\mathrm{pH}$ values of the medium and in different solvents is of fundamental importance for the industrial use of hypochlorite technology as an alternative to the cyanide process.

\section{Experimental}

In a series of experiments to study the kinetics of the leaching process of a model gold electrode, gold plate $(99,999 \%)$ with a size of 15 by 10 by $1 \mathrm{~mm}$ were used, and they were rotated at a speed of $80 \mathrm{rpm}$; reproducible hydrodynamic conditions of intensified reactant supply to the dissolving gold surface were thus set up. Working hypochlorite solutions were prepared by diluting a standard solution (containing $18,4 \%$ of $\mathrm{NaOCl}$ and $14,1 \%$ of $\mathrm{NaCl}$ ) with twice-distilled water. The studies were carried out in a hermetically sealed thermostatically controlled (to an accuracy of $\pm 0,5^{\circ} \mathrm{C}$ ) electrolytic cell. For each experiment, fresh chloride-hypochlorite solution of present composition and $\mathrm{pH}$ was taken. The dissolution kinetic curves were plotted from the data on the amount of gold passed into the solution for a specified time interval. The amount of dissolved gold was determined by gravimetric or atomic-adsorption method. The surface films constituted by the gold oxidation products $\left(\mathrm{AuCl}, \mathrm{AuOH}, \mathrm{AuCl}(\mathrm{OH})^{-}\right) \approx 200 \mu \mathrm{m}$ thick were studied with the use of a JAMP-10S Auger electron-spectrometer (JEOL, Japan). The studied solution in the cell has a volume of $40 \mathrm{~cm}^{3}$.

The second series of experiments was devoted to the study of the processes of leaching by sodium hypochlorite of native gold obtained by gravitational sedimentation on industrial dredges at one of the polymetallic deposits in Ghana (Africa, the mount of the Volta River). Native gold is rounded grains of irregular shape with a size from 5 to 2500 microns, on the surface of which fine particles of accompanying minerals are adsorbed quartz $\left(\mathrm{SiO}_{2}\right)$, calcium carbonate $\left(\mathrm{CaCO}_{3}\right)$, aluminum oxide $\left(\mathrm{Al}_{2} \mathrm{O}_{3}\right)$ and others. It is assumed that alumina is located on the surface of gold grains not in the form of separate conglomerates, but in the form of a carbonaluminosilicate film tightly adsorbed ("intergrown") with the gold surface, which creates a serious technological problem in gold leaching. The chemical composition of the surface layer of native gold are shown in table 1 . 
Chemical composition of the surface layer of native gold from a polymetallic deposit (Ghana, equatorial Africa, the mouth of the Victoria River) ${ }^{*}$

\begin{tabular}{c|c|c|c|c|c|c}
\multirow{2}{*}{ Element } & \multicolumn{2}{|c|}{ Sample 1 } & \multicolumn{2}{c|}{ Sample 2 } & \multicolumn{2}{c}{ Average values } \\
\cline { 2 - 7 } & mass \% & atomic\% & mass \% & atomic\% & mass \% & atomic\% \\
\hline $\mathrm{C}$ & 7,62 & 37,38 & 7,16 & 32,59 & 7,39 & 35,6 \\
\hline $\mathrm{O}$ & 9,46 & 34,86 & 11,23 & 38,41 & 10,34 & 37,0 \\
\hline $\mathrm{Al}$ & 0,54 & 1,18 & 0,47 & 0,95 & 0,505 & 1,1 \\
\hline $\mathrm{Ca}$ & 1,65 & 2,42 & 0,93 & 1,27 & 1,29 & 1,9 \\
\hline $\mathrm{Si}$ & - & - & 2,69 & 5,24 & 1,345 & 1,4 \\
\hline $\mathrm{Au}$ & 80,73 & 24,16 & 77,53 & 21,54 & 79,13 & 23,0 \\
\hline $\mathrm{c}$ & 100,00 & 100,00 & 100,00 & 100,00 & 100,00 & 100,00 \\
\hline
\end{tabular}

*- elemental composition according to computer analysis data INCA Energy SEM "Oxford Instruments"

\section{Result and discussion}

In Fig. 1 we give a dependence of the rate of the redox leaching of the rotating model gold plate in hypochlorite solutions $(6,0 \%$ $\mathrm{NaCl}, \mathrm{n} M \mathrm{HCl}$ ) on the $p H$ of the solution at $298 \mathrm{~K}$. The results are shown after contact of the plate with the leach solution for $5 \mathrm{~min}$. When diluting the solution, the chloride ion concentration was decreased to $4,71 \%\left(47,1 \mathrm{~g} / \mathrm{dm}^{3}\right)$; the $p H$ value was controlled by adding $\mathrm{HCl}$. According to the graph, the rate of redox leaching of gold $\left(v_{\mathrm{Au}}\right)$ in chloride-hypochlorite solutions has a non-linear dependence on the $\mathrm{pH}$ of the medium. At extremely low $\mathrm{pH}(\mathrm{pH}$ $1,8)$, gold undergo leaching at a rate of $600 \mathrm{~g} \cdot \mathrm{m}^{-2} \cdot \mathrm{h}^{-1}$. This indicator is almost two times inferior to the rate of dissolution of gold in aqua regia, which is $1320 \mathrm{~g} \cdot \mathrm{m}^{-2} \cdot \mathrm{h}^{-1}$ at room temperature [4].

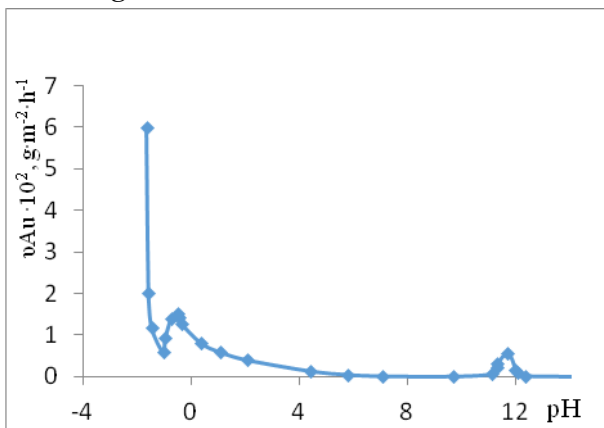

Fig.1. The solution $\mathrm{pH}$ dependence of gold leaching rate $v_{\mathrm{Au}}$ in sodium hypochlorite $(6,0 \% \mathrm{NaCl}, \mathrm{nM} \mathrm{HCl})$ at $298 \mathrm{~K}$ 
With an increase in $p H$, the dissolution rate drops down abruptly to a sharp minimum $\left(\approx 60 \mathrm{~g} \cdot \mathrm{m}^{-2} \cdot \mathrm{h}^{-1}\right.$ at $\left.\mathrm{pH}-1,0\right)$. Further, it equally abruptly grows up, coming to $154 \mathrm{~g} \cdot \mathrm{m}^{-2} \cdot h^{-1}$ at $p H-0,2$. With a further increase in $p H$, the dissolution rate gradually drops down to a flat minimum ( 110 to $120 \mathrm{~g} \cdot \mathrm{m}^{-2} \cdot \mathrm{h}^{-1}$ ) in a $\mathrm{pH}$ range from 9 to 12 . In a range of $p H 12,5-14,5$ the dissolution rate $v_{\mathrm{Au}}$ again passes a maximum: $5,6 \mathrm{~g} \cdot \mathrm{m}^{-2} \cdot \mathrm{h}^{-1}$ at $\mathrm{pH} 13,5$.

The initial sharply descending segment of the graph in Fig. 1 (in a $p H$ range from $-1,8$ to $-1,0$ ) is of no interest for practical workers because of too high concentration of hydrochloric acid and, hence, the corrosivity of the solution approaching aqua regia in its acting components and their properties. The next sharply ascending segment is of equally low interest, because the range of dissolution rates demonstrated here is covered backward in the successive descending segment, where the acid concentration appears appropriate.

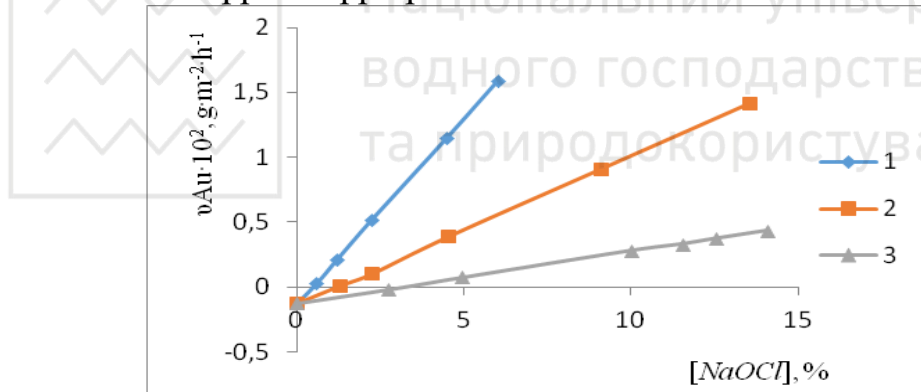

Fig. 2. Dependence of gold leaching rate $v_{\mathrm{Au}}$ in hypochlorite solutions on the hypochlorite concentration [NaJCl] at $298 \mathrm{~K}$. The solution $\mathrm{pH}$ : (1) 1,06, (2) 4,15 and (3) 6,65

The effect of hypochlorite-concentration on the gold leaching rate at different $p H$ is shown in Fig. 2. The dependence is visualized as a bunch of straight lines with a common $Y$-intercept below the origin and can be described by a general equation

$$
v_{A u}=-0,12+\operatorname{tg} \alpha \cdot[\mathrm{NaOCl}], g \cdot m^{-2} \cdot h^{-1},
$$

where $\operatorname{tg} \alpha$ - the tangent of the slope of the curve in Fig. 2; $[\mathrm{NaJCl}]$ - concentration of sodium hypochlorite in solution (\%); “0,12 " - the point of intersection of the ordinate $(Y)$ by the curves of the graph at zero concentration of $\mathrm{NaCl}$. 
The slope of the curves at different $p H$ values of solutions characterizes the change in the rate of gold leaching $v_{\mathrm{Au}}$. The tgaat $p H$ of $1,06,4,15$, and 6,65 equals $0,267,0,107$, and 0,025 , respectively, that is, decreases by more than order of magnitude. The given data indicate that in a solution containing $6 \%$ of sodium hypochlorite and $4,71 \%$ of sodium chloride, with a decrease in $\mathrm{pH}$ from 6,65 to 1,06 , the gold leaching rate $v_{\mathrm{Au}}$ increases by a factor of 26,7 .

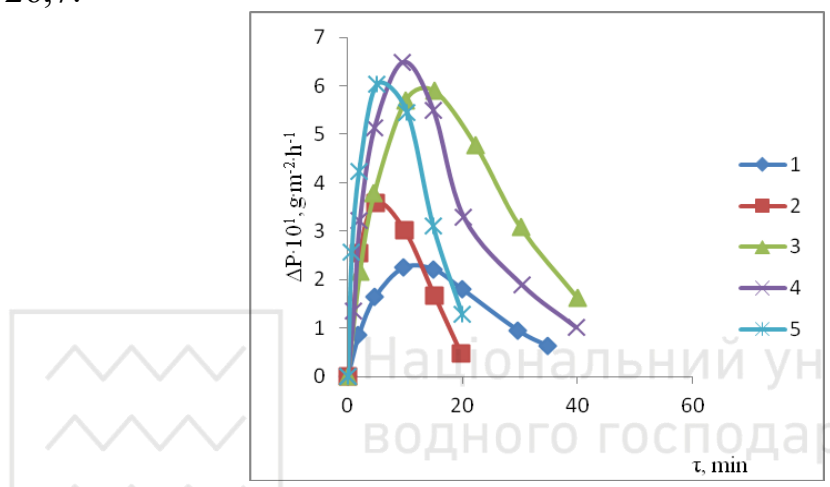

Fig. 3. Kinetic curves of the gold leaching rate in chloride-hypochlorite solutions $(6,0 \% \mathrm{NaOCl}, 0,1 \mathrm{M} \mathrm{NCl}, p H 1,06-1,12)$ at different temperatures $(K):(1)$ 289, (2) 297, (3) 304, (4) 313, and (5) 333

Shown in Fig. 3 data are kinetic dissolution curves $\left(\Delta P-\tau_{i}\right)$ for a gold electrode (plate) with surface area $S=1,0 \mathrm{~cm}^{2}$ at temperatures 277, 289, 304, and $333 \mathrm{~K}$. It's obvious that the kinetic curves are composite functions of time. For example, at 277 and $289 K$, the sample mass losses $\Delta P-\tau_{i}$ during the initial period abruptly increase, reaching their maxima $\left(\Delta P_{\max }\right)$ of 22,5 and $58,5 \mathrm{~g} \cdot \mathrm{m}^{-2}$, respectively, after a lapse of $\tau_{\mathrm{i}}=15 \mathrm{~min}$. At temperature of 304, 313, or $333 \mathrm{~K}$, the $\Delta P_{\max }$ values: $65,60,5$, and $36 \mathrm{~g} \cdot \mathrm{m}^{-2}$ were reached for 10,6 , and $5 \mathrm{~min}$, respectively. Figure 3 shows that the sample mass loss decreased significantly (down to $\Delta P=5$ to $16 \mathrm{~g} \cdot \mathrm{m}^{-2}$ ), due to the gold passivation. 


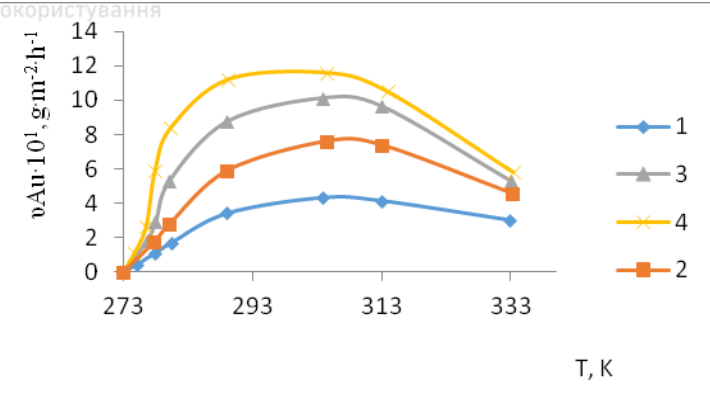

Fig. 4. Dependence of gold dissolution rate in hypochlorite solutions $(6,0 \% \mathrm{NaOCl}, 0,1 \mathrm{M} \mathrm{HCl}, p H 1,06-1,12)$ on the temperature and the gold exposure time ( $\tau$, min): (1) 5 , (2) 10 , (3) 15 , (4) 20

Shown in Fig. 4 data are temperature dependence of the gold leaching rate in $6,0 \% \mathrm{NaOCl}, 0,1 \mathrm{M} \mathrm{HCl}(4,06 \%$ of $\mathrm{NaCl})$ solution with $p H 1,06-1,12$. We see that the " $v_{\mathrm{Au}}-\mathrm{T}$ " curves pass a maximum; the decay of $v_{\mathrm{Au}}$ is more strongly pronounced at higher temperatures. In the initial segment of the dissolution curves, at $\tau_{i}<\tau_{\max }$, that is, before the passivation, the gold ion concentration $C_{\max }$ can be described by the equation

$$
C=C_{\max }\left(1-e^{-k \tau}\right),
$$

which corresponds to the first-order kinetic equation [1]. Therefore, in determining the rate constants $k_{i}$ of the gold leaching, we used the initial period, i.e., until the concentration changed at the electrode surface.

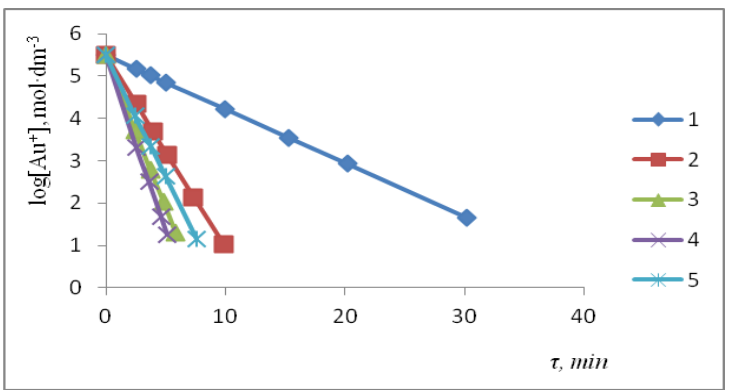

Fig. 5. Dependence of the logarithm of concentration of gold (I) ions formed during the gold leaching in chloride-hypochlorite solutions $(5.3 \% \mathrm{NaCIO}, 0.1 \mathrm{M} \mathrm{HCl}, \mathrm{pH}$ 1.06-1.12) on the gold exposure time at different temperatures (K): (1) 277, (2) 289, (3) 304, (4) 313 , and (5) 333 
All experimental curves taken during the initial period of gold dissolution in the studied chloride-hypochlorite solutions clearly can be linearized in an a " $\log [\mathrm{Au}]=f\left(\tau_{i}\right)$ " (Fig. 5), which corresponds to the equation (2).

The rate constants $k_{\mathrm{i}}$ were calculated from the slopes of the initial segments of the lines; they equal $0,0790,0,2695$, and $0,4030 h^{-1}$ for temperatures 277,298 , and $304 K$, respectively. The temperature dependence of the rate constants " $\log k_{i}=f\left(\frac{1}{T}\right)$ ' '“", calculated in a temperature range from 277 to $304 K$, as well as the apparent activation energy $E_{a}=40,3 \mathrm{~kJ} / \mathrm{mol}$, evidences a diffusion-kinetic control of the gold leaching. From the slopes of the " $\log [\mathrm{Au}]=f\left(\tau_{i}\right)$ " we calculated the rate constants. For temperature of 313 and $333 K$, they equal 0,2510 and $0,3293 h^{-1}$, respectively. The values are lower than those found at temperatures of 289 and $304 \mathrm{~K}$.

The results of our research indicate that the maximum gold leaching rate is achieved at $304 \mathrm{~K}$, with a further increase in temperature, up to 313 and $333 K$, it decreases. Such a run of the kinetic curves cannot be ascribed to a loss of the chloride-hypochlorite solution reactivity. I each experiment, fresh chemicals were used. Special experiment showed that at $\mathrm{pH}-1,8,-1,0,-0,5,0,0$, and 1,0 , the molecular chlorine losses according to equations came to $3,1,2,6$, $1,7,0,6$, and $0,01 \mathrm{vol} . \%$, respectively (for $\tau_{\max }=40 \mathrm{~min}$ ). The gold leaching efficiency (calculated by the hypochlorite consumed) was $96-99 \%$ over the entire $p H$ range studied (from $-1,8$ to 1,0 ).

$$
\begin{aligned}
& \mathrm{NaOCl}+\mathrm{Cl}^{-}+\mathrm{H}^{+} \stackrel{+e^{-}}{\stackrel{0}{\mathrm{C}} l_{2} \uparrow}+\mathrm{OH}^{-}+\mathrm{Na}^{+}, \\
& \stackrel{+1}{\mathrm{HOCl}}+\mathrm{Cl}^{-}+\mathrm{H}^{+} \stackrel{ \pm e^{-}}{\longleftrightarrow} \stackrel{0}{\mathrm{Cl}} l_{2} \uparrow+\mathrm{H}_{2} \mathrm{O},
\end{aligned}
$$

When studying the processes of leaching native gold with sodium hypochlorite $\mathrm{NaOCl}$, a mixture of reagents was used, which, in terms of their physicochemical properties, can simultaneously function as both oxidizing agents and reducing agents.

Depending on the $\mathrm{pH}$ of the medium, the type of solvent and the strength of the electrolyte, the direction of the voltage-dependent redox reaction can change and the final products from the same initial components can be completely different [3]. Therefore, for the processing of native gold, methodological techniques were used that 
fundamentally differed from the technology of leaching a model gold disk, consisting of exclusively pure gold (99.999\%). Taking into account the fact that on the surface of native gold, we also discovered other chemical elements (except for gold), the nature of the interaction of which with the gold surface is rather complicated and ambiguous, therefore, the method of leaching the target element was modified. For this, the technological process was divided into three stages:

Stage 1: mechanical activation of the gold surface (complex chemical and mechanical destruction of the surface carbonaluminosilicate film) using sodium hypochlorite solution with an extremely alkaline $p H$ value $(p H>12,0)$.

Stage 2: leaching of the target element with sodium hypochlorite dissolved in glacial acetic acid $\mathrm{CH}_{3} \mathrm{COOH}(p H=6,8-7,0)$, with the addition of hydrogen peroxide $\left(\mathrm{H}_{2} \mathrm{O}_{2}\right)$.

Stage 3: reduction of the target element to the metallic state by acidifying the leaching solution to $p H<2,0$ (growing hexagonal lamellar gold crystals).

At the first stage - complex mechanical activation, reactions occur that free the gold surface from the oxide film:

$$
\begin{gathered}
\mathrm{Al}_{2} \mathrm{O}_{3}+2 \mathrm{NaOH}=2 \mathrm{NaAlO}_{2}+\mathrm{H}_{2} \mathrm{O}, \\
\mathrm{NaAlO}_{2}+2 \mathrm{H}_{2} \mathrm{O}=\mathrm{Al}(\mathrm{OH})_{3}+\mathrm{NaOH} ; \mathrm{pH}>7,0 .
\end{gathered}
$$

In this case, water-soluble complex salts are formed - sodium aluminate and aluminum hydroxide hydrolysable in an aqueous medium.

At the second stage, in fact, the leaching of metallic gold occurs, which is a reducing agent for the chlorine ion $\left(-{ }^{+1}-\right)$, which is part of hypochlorite, (i.e., gold is an electron donor (anode), and an electron acceptor is a chlorine ion (cathode) included in composition of sodium hypochlorite):

$$
\stackrel{0}{\mathrm{Au}}+\mathrm{NaOH}+1 \frac{1}{2} \mathrm{NaOCl} \stackrel{+1}{\longrightarrow} \stackrel{-3 \mathrm{e}^{-}}{\longrightarrow} \mathrm{Na}\left[\stackrel{+3}{\mathrm{AuO}_{2}}\right]+1 \frac{1}{2} \mathrm{Na}^{\mathrm{Cl}}+\frac{1}{2} \mathrm{H}_{2} \mathrm{O} .
$$

In this case, sodium aurate is formed - a complex oxide of sodium and gold (crystalline hydrate), easily soluble in water. 
At the third stage, gold is restored from salt - sodium aurat $\stackrel{+3}{\left.\mathrm{AuO}_{2}\right]}$; hydrogen peroxide $\left(\mathrm{H}_{2} \mathrm{O}_{3}\right)$ is used as a reducing agent in the presence of dehydrated organic acid $\left(\mathrm{CH}_{3} \mathrm{COOH}\right)$

$$
\mathrm{Na}\left[\stackrel{+3}{\mathrm{AuO}_{2}}\right]+1 \frac{1}{2} \mathrm{H}_{2} \stackrel{-1}{\mathrm{O}}_{2}+\mathrm{CH}_{3} \mathrm{COOH} \stackrel{+3 \mathrm{e}^{-}}{\longrightarrow} \stackrel{0}{\mathrm{Au}} \downarrow+\mathrm{CH}_{3} \mathrm{COONa}+1 \frac{1}{2} \stackrel{0}{\mathrm{O}_{2}} \uparrow+2 \mathrm{H}_{2} \mathrm{O} \cdot
$$

In this reaction, the electron donor is oxygen $\left(-{ }^{-1}\right)$ (anode), which is part of hydrogen peroxide, and the electron acceptor is the gold atom $\left(\left[=\mathrm{Au}_{-}^{+3}\right]\right)$ (cathode), which is part of sodium aurate. The fundamental condition for an effective one-sided transition of the reaction (irreversibility of the reaction) is a moderately acidic $p H$ value $(\sim 2,0)$, the presence of a "weak" organic acid, which ensures the irreversibility of the reaction, as well as the unhindered removal of oxygen outside the reaction medium. In this case, in a reaction vessel (quartz, heat-resistant glass), after cooling the medium to room temperature for 16-18 hours, triangular shapes, plate-like up to $163 \times 163 \mu \mathrm{m}$ in size (Fig. 8). The latter are easily separated from gold crystals by washing the precipitate with warm distilled water.

It is quite remarkable that the active growth of crystals of reduced metallic gold under these conditions does not depend on the presence of biopolymer or other gel-forming matrices, which are traditionally used in the growth of gold crystals $[7,8]$.

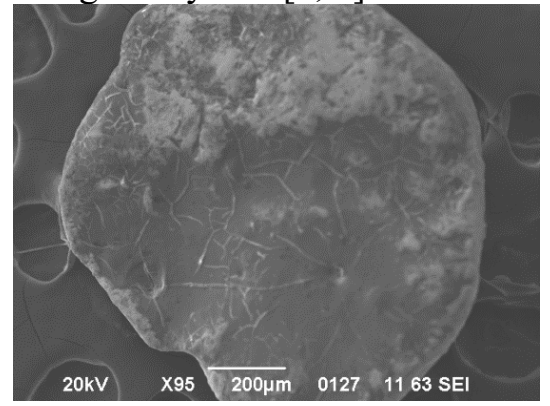

Fig. 6. Electron micrograph of native gold grain 1,35 by $1,1 \mathrm{~mm}$ in size (scanning electron microscopy, magnification x95)

On the surface of native gold, accompanying elements were found - carbon $(\mathrm{C})$, oxygen $(\mathrm{O})$, silicon $(\mathrm{Si})$, calcium $(\mathrm{Ca})$, and aluminum (Al), the presence of which is due to adsorbed microdispersed or nanodispersed particles of calcite $\left(\mathrm{CaCO}_{3}\right)$, quartz 
$\left(\mathrm{SiO}_{2}\right)$ and aluminum oxide $\left(\mathrm{Al}_{2} \mathrm{O}_{3}\right)$. On the surface of the gold (in the lower part, on the right), a small "crater" is visible - the point of a short (3-4 minutes) exposure to the scanning beam of an electron microscope. At this point, a local overheating of the surface occurred (up to several hundred degrees), as a result of which a fairly stable carbon-aluminosilicate film began to collapse. In this case, the emerging cracks are clearly visible, diverging radially from the "crater". This phenomenon indicates the real presence of a protective oxide film, which complicates the leaching of native gold.

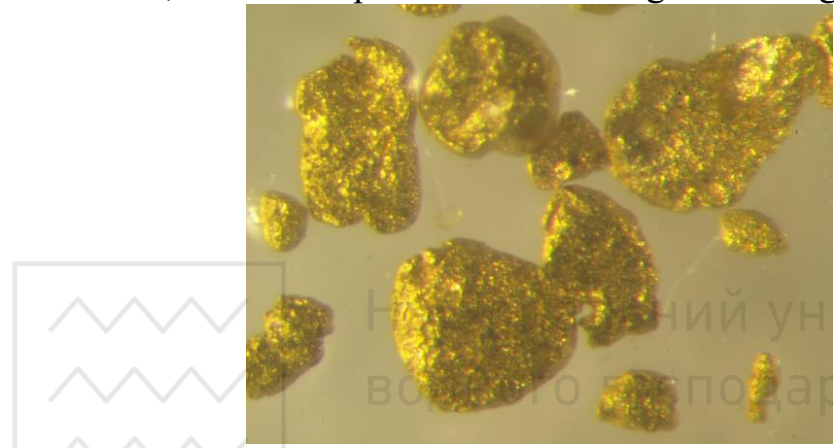

Fig. 7. Monomineral fraction of native goldfinches from an alluvial polymetallic deposit (Ghana, equatorial Africa). Dimensions of gold coins from $0,1 \times 0,2 \mathrm{~mm}$ to $1,5 \times 2,0 \mathrm{~mm}$ (stereomicroscopy, magnification $\mathrm{x} 56$ )

On native gold grains, even when using a light microscope, it is not possible to detect a protective oxide film - it is quite thin and does not differ in color from the matrix.

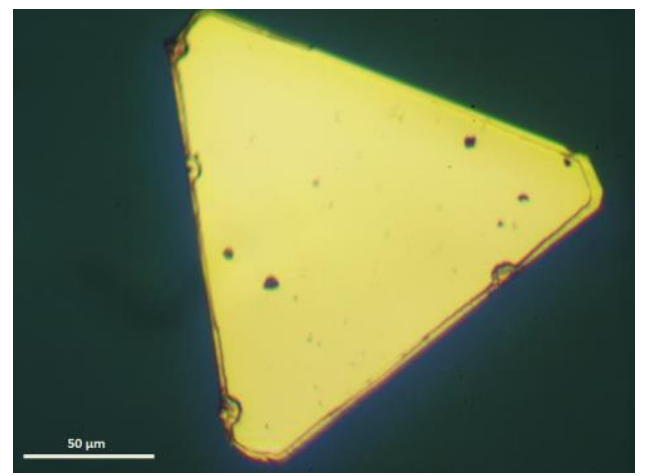

Fig. 8. The characteristic triangular shape of a crystal of metallic gold grown from a solution of gold grains, shown in Fig. 7, underwent a processing cycle according to reactions (5), (6), 
(7), and (8). Crystal shape and size of extremely correct symmetry (163×163×163 microns). Polarizing microscopy (magnification x320) "Karl Zeiss", Jena

\section{Conclusions}

Working on this problem - the development of a hypochlorite method of gold leaching, the authors of this article saw for themselves - how important it is for scientists to work with safe, nontoxic, environmentally friendly reagents.

Work on this topic began in the 90s of the twentieth century. And thanks to our predecessors, our older colleagues, most of whom are no longer near the banner, we were able to complete this development, the results of which would be satisfied by our older friends.

Over time, this development will be improved by our successors however, what we have managed to do, allows us to say that it is not in vain that we went to science and not in vain learned something.

References

1. Kozin L.F. Kinetics and mechanism of the gold corrosion dissolution in hypochlorite solutions / L.F. Kozin, V.A. Prokopenko, A.K. Bogdanova // Protection of Metals. - 2005. - V.41, N1. - P.22-29. Translated from Zashchita Metallov (Russia). - 2005. - V.41, N1. - P.26-33.

2. Habashi F. Kinetics and mechanism of gold and silver dissolution in cyanide solution / Bureau of Mines and Geology. State of Montana / Bulletin 59. - 1967. - 42 p.

3. Solvent as a means of controlling the chemical process / Yu.Ya. Fialkov. Leningrad: Chemistry, 1990. - 240 p.

4. Salimi H. Gold leaching in organic solvents: simple and mild reaction conditions for fast gold dissolution / COM 2015. The conference of metallurgists // America's conference on aluminum alloys. - 2015. (Published by the Canadian Institute of Mining, Metallurgy and Petroleum / www.metsoc.org ).

5. Crundwell F.K. A mathematical model of the leaching of gold in cyanide solutions / F.K. Crundwell, S.A. Godorr // Hydrometallurgy. - 1997. - V.44. P.147-162.

6. Jeffrey M.I. A kinetic study that compares the leaching of gold in the cyanide, thiosulfate and chloride systems / M.I. Jeffrey, P.L. Breuer, W.L. Choo // Metallurgical and Materials Transactions. - 2001. - B. - 32B. - P.979 - 986.

7. Kratochvil P. Growth of gold single crystals in gels / P. Kratochvil, B. Sprusil // J. Crystal Growth. - 1968. - V.3, 4. - P. 360-362.

8. Estrela-Llopis V.R. Extracellular mineralization and synthesis of microcrystallites of gold and platinum in aqueous solutions of polysaccharides / V.R. Estrela-Llopis, T.I. Borodinova, I.N. Yurkova in the book: Colloidal- 
chemical foundations of nanoscience / Shpak A.P., Z.R. Ullberg (ed.). - Kiev: Akademperiodika, 2005 . - P. 271-297

9. Chernenko V.Yu. Thermodynamic basis of environmentally-friendly technology of dissolution of carbonic polyminerals by biogenic agents / V.Yu. Chernenko, I.M. Astrelin I.M. // Research bulletin of the National Technical University of Ukraine "Kyiv Polytechnic Institute". - 2010. - №5 (73). - P. 145-152. 